\title{
ARTICLE \\ Spinal cord injury rehabilitation patient and physical therapist perspective: a pilot study
}

\author{
Martha M Sliwinski ${ }^{1}$, Ryan Smith ${ }^{2,4}$ and Andrea Wood ${ }^{3,4}$
}

The objectives of this retrospective observational study were to explore physical therapists' perceived involvement of patients with $\mathrm{SCl}$ in physical therapy (PT) rehabilitation, second to explore individuals with SCI perceived involvement in PT rehabilitation, third to compare how patients and physical therapists perceive involvement in PT rehabilitation and last to explore patients' perceived involvement with satisfaction with life (SWL). This study was conducted in the United States. Two 11-item questionnaires were designed one for physical therapists and one for patients. The items were rated on a Likert-type agreement scale. Thirty physical therapists completed the patient involvement questionnaire for physical therapists and nine individuals with $\mathrm{SCl}$ completed the patient involvement questionnaire and SWL scale. We certify that all applicable governmental and institutional guidelines were followed during the course of this research. The results indicated that both physical therapists and patients were overall in agreement that patients were involved in their PT rehabilitation on most items. The two items that received the lowest Likert scores by the therapists and patients were friends and family involvement in therapy and gender-related issues. The item, individualized patient goals, received the largest discrepancy between therapists and patients. The sample size was too small to observe a trend with SWL and perceived involvement. Patients and PTs from this pilot overall agree patients are included in treatment; however, the discrepancy in scores related to individualized goals requires further research.

Spinal Cord Series and Cases (2016) 2, 15036; doi:10.1038/scsandc.2015.36; published online 7 April 2016

\section{INTRODUCTION}

Involving patients in rehabilitation is a necessary component of the process to assist individuals in meeting their desired goals for community integration. Spinal cord injuries $(\mathrm{SCls})$ result in neurological deficits requiring the services of interdisciplinary medical professions, most importantly the rehabilitation team. Each patient's method of adapting to $\mathrm{SCl}$ will be unique and very individualized. Social, psychological and emotional implications as well as level of disability impact an individual's recovery. ${ }^{1-3}$ These factors can have an impact on an individual living with $\mathrm{SCl}^{\prime} \mathrm{s}$ satisfaction with life (SWL). The inpatient rehabilitation process can help an individual with $\mathrm{SCl}$ adjust and cope with the new changes in his life secondary to his injury. ${ }^{4}$ Physical therapists have an active role in rehabilitation promoting the goal of community reintegration in individuals with $\mathrm{SCl}^{1}{ }^{1}$

According to Papadimitriou, ${ }^{4}$ patients undergo a process of habituating to the world from a new physical perspective, participating in activities using new skill strategies. New ways of acquiring these skills occurs with therapists physically engaging and communicating in action as new methods are practiced. ${ }^{4}$ Effective practice requires that clinicians interact with their patients in ways that make them feel included in their rehabilitation and tailor treatments towards the patient's individual goals.

Several studies have explored factors that are necessary for a successful rehabilitation experience. ${ }^{2,5-8}$ Functional abilities, incidences of re-hospitalization and marital status have been identified as predictors of patient satisfaction with rehabilitation. ${ }^{5}$
Individuals with improved functional status were more satisfied with their medical rehabilitation, versus those whose expectations in rehabilitation were not met. ${ }^{5}$ Three important priority areas during rehabilitation as perceived by individuals with $\mathrm{SCl}$ include participation, information and relationship. ${ }^{2}$ In another study, Ripat and Woodgate $^{6}$ interviewed 19 adults with SCl who described participation in four ways: inclusion, opportunity for reciprocity, accomplishment and autonomy. Active participation in the rehabilitation process as proposed by Pellat ${ }^{7}$ places patients as equal members of the rehabilitation team. Therefore, it appears that a holistic approach to care that is carefully planned without professional boundaries such that information is not delivered piecemeal is necessary for a therapeutic environment. ${ }^{8}$

SWL after SCl has been found to be effected by a patient's involvement in their rehabilitation; however, limited research has explored this connection., ${ }^{5,8}$ Success during rehabilitation will often have a large role in SWL for an individual living with $\mathrm{SCl}{ }^{1}$ A recent meta-analysis found that specific qualities of the rehabilitation institution such as inflexible policies, processes involving making decisions, procedures and organizational practices directly influence the ability for a patient with $\mathrm{SCl}$ to visualize a capable future. ${ }^{10}$ Patients with $\mathrm{SCl}$ valued those therapists who worked directly with them to set goals that were important and specific to the individual. In addition, patients identified several negative aspects in traditional rehabilitation programs, including exaggerated focus on the physical aspect of $\mathrm{SCl}$, a lack of attention to the individual and the inability to prepare the individual to their needs in the real world. ${ }^{10}$

\footnotetext{
${ }^{1}$ Department of Rehabilitation and Regenerative Medicine, Columbia University Medical Center, Program in Physical Therapy, New York, NY, USA; ${ }^{2}$ Physical Therapy Department, Adirondack Medical Center, Lake Placid, NY, USA and ${ }^{3}$ New Dimensions Physical Therapy, Manhasset, NY, USA.

Correspondence: MM Sliwinski (ms2814@cumc.columbia.edu)

${ }^{4}$ These authors contributed equally to this work.

Received 25 August 2015; revised 11 October 2015; accepted 30 October 2015
} 
Recently, patient participation has been defined as including five keystones: getting to know a patient and treating them as an individual, helping to motivate a patient, giving the patient a chance to make decisions by themselves, keeping the patient well informed, and involving the patient's family. ${ }^{3}$ Although patient involvement and satisfaction with rehabilitation has been explored, no studies have compared physical therapists' (PTs') and patients' perceived involvement in the rehabilitation process. The aims of this pilot study were first to describe the physical therapist's perceived involvement of their patients in rehabilitation, and second, to explore individuals with SCl's perceived involvement in their rehabilitation. The third purpose was to compare how PT's and patients perceived involvement in the inpatient PT rehabilitation process. Finally, patients' perceived involvement in rehabilitation and SWL scores were compared.

\section{MATERIALS AND METHODS}

\section{Survey questionnaires}

Two questionnaires were designed, one for physical therapists and one for individuals with a $\mathrm{SCl}$. The questionnaires were designed with input from a research expert in the field of $\mathrm{SCl}$, a physical therapist in academia with an expertise in $\mathrm{SCl}$ and physical therapists in the field working with $\mathrm{SCl}$. The patient involvement questionnaire and PT questionnaire were designed simultaneously. The 11-item questionnaires included specific questions on patients' perspective of their involvement during their inpatient PT experience. The items were rated on a Likert-type agreement scale ( $1=$ strongly disagree, $5=$ strongly agree) (Table 1$)$. The questions for the PT questionnaire were written in a negative manner, 'I do not...' to request a comment from the PT, and therefore the scale was reversed. The designers of the survey felt that the negative wording would assist PTs in reflecting on specific examples and comments that might help the authors gain a better understanding of how therapists felt they involved their patients in rehabilitation. The authors anticipate that the results of this survey will assist in designing another survey version for future validation.

In addition to the patient involvement questionnaire, the participants also completed the satisfaction with life scale (SWLS). ${ }^{11}$ The SWLS includes five items that specifically look at subjects' overall life fulfillment. The scale uses a seven-point ranking ( $1=$ strongly disagree, $7=$ strongly agree). The internal consistency of the SWLS was found to be good in a study of
145 patients 5 years after discharge. ${ }^{12,13}$ The SWLS is the most established measure, offering the comparison of results with other population studies. ${ }^{13}$

\section{Subjects or participants}

Thirty licensed physical therapists that have been treating the $\mathrm{SCl}$ population for at least 3 months volunteered to complete the questionnaire. They represented three hospitals in the greater New York metropolitan area. Nine participants with $\mathrm{SCl}$ volunteered to complete the questionnaire meeting the following inclusion criteria: 18 years or older, injury was at least 3 months but not $>5$ years ago, discharged from inpatient rehabilitation, no surgery within the past 2 months, no current stabilization device and used a wheelchair as their primary mode of transportation. The Institution Review Board of Columbia University approved this study.

\section{Procedure}

Potential study volunteers responded to either the study flier or an Internet posted flier. Subjects that met the study inclusion criteria were informed that the interview process might take $20-40 \mathrm{~min}$. Consenting participants could choose to be interviewed via telephone or schedule an appointment time with the researchers. Only members of the research team conducted interviews using a standard script and following the established research protocol sheet. The researchers followed this protocol sheet throughout the interview to decrease the variability in their approach to the questions and maintain inter-rater reliability.

Each patient and physical therapist were first required to complete a demographic form. They were then asked to complete a questionnaire designed for the study concerning their perception of the patient's involvement during rehabilitation (Table 1). All participants completed the survey via telephone or in-person interview. If the participant did not offer an example, they were asked to provide one to support the ranking.

\section{Data analysis}

Descriptive statistics were used to compile the data. Two PT research students analyzed patient and physical therapist questionnaires. All quantitative data was transferred to a spreadsheet application (Microsoft Excel, Redmond, WA, USA) for organization and review. The reported raw scores of both groups for individual survey items on the patient involvement questionnaire and SWLS were totaled. In addition,

Table 1. Survey items for physical therapists and patients

\begin{tabular}{|c|c|c|}
\hline Survey Item & Physical therapists & Patients \\
\hline \multicolumn{3}{|c|}{ Patient's involvement in treatment planning and individualized care } \\
\hline 1 & $\begin{array}{l}\text { I don't involve patients in the planning of their PT } \\
\text { treatment. }\end{array}$ & My physical therapist involved me in the planning of rehabilitation. \\
\hline 2 & $\begin{array}{l}\text { I don't encourage patients to become involved in their PT } \\
\text { treatment and to ask questions. }\end{array}$ & During treatment sessions, my input was valued and listened to. \\
\hline 3 & $\begin{array}{l}\text { I don't take into account the patient's individual goals when } \\
\text { setting my therapeutic goals. }\end{array}$ & $\begin{array}{l}\text { My personal goals for rehabilitation were taken into account for } \\
\text { planning of treatment. }\end{array}$ \\
\hline 4 & $\begin{array}{l}\text { I don't explain the purpose of PT treatments to the patient } \\
\text { before beginning. }\end{array}$ & $\begin{array}{l}\text { The purpose of treatments were explained to me before performing } \\
\text { activity. }\end{array}$ \\
\hline 7 & $\begin{array}{l}\text { I don't take into account the patient's personal interests } \\
\text { when planning my treatment sessions. }\end{array}$ & My physical therapist involved my personal interests into my treatment. \\
\hline 8 & $\begin{array}{l}\text { I feel this facility is committed to involving patients in the } \\
\text { planning and goal setting for their individual therapy. }\end{array}$ & $\begin{array}{l}\text { I felt as though my physical therapist approached me as an individual } \\
\text { with specific needs and designed my treatment according to that. }\end{array}$ \\
\hline 10 & I don't develop a positive rapport with my patients. & I had a good relationship with my physical therapist. \\
\hline \multicolumn{3}{|c|}{ Community preparation } \\
\hline 5 & $\begin{array}{l}\text { I don't take into account the patient's living situation after } \\
\text { discharge to personalize PT treatment. }\end{array}$ & $\begin{array}{l}\text { My physical therapist asked me about my personal living situation after } \\
\text { discharge. }\end{array}$ \\
\hline 6 & $\begin{array}{l}\text { I don't involve the patient's family/friends in their PT } \\
\text { therapy. }\end{array}$ & My friends/family were involved in my therapy. \\
\hline 9 & $\begin{array}{l}\text { I don't feel that I adequately prepare my patients for } \\
\text { functioning in the community after discharge. }\end{array}$ & $\begin{array}{l}\text { I felt as though my physical therapist adequately prepared me for } \\
\text { functioning in the community after discharge. }\end{array}$ \\
\hline \multicolumn{3}{|c|}{ Gender-specific needs } \\
\hline 11 & I don't address my patient's gender-specific needs. & $\begin{array}{l}\text { I felt as though my gender-specific needs were addressed by my } \\
\text { physical therapist. }\end{array}$ \\
\hline
\end{tabular}




\begin{tabular}{|c|c|}
\hline \multicolumn{2}{|l|}{ Sex } \\
\hline Male & $n=8$ \\
\hline Female & $n=1$ \\
\hline \multicolumn{2}{|c|}{ Age range (years) } \\
\hline $19-29$ & $n=3$ \\
\hline $30-39$ & $n=3$ \\
\hline $40-50$ & $n=3$ \\
\hline \multicolumn{2}{|c|}{ Time since injury (months) } \\
\hline$<12$ & $n=2$ \\
\hline $12-24$ & $n=5$ \\
\hline$>24$ & $n=2$ \\
\hline \multicolumn{2}{|c|}{$\mathrm{SCl}$ characteristics } \\
\hline Complete & $n=3$ \\
\hline Incomplete & $n=6$ \\
\hline Paraplegia & $n=8$ \\
\hline Tetraplegia & $n=1$ \\
\hline \multicolumn{2}{|c|}{ Level of injury (spinal segments) } \\
\hline $\mathrm{C} 6-\mathrm{C} 7$ & $n=1$ \\
\hline C8-T4 & $n=4$ \\
\hline T5-T10 & $n=4$ \\
\hline \multicolumn{2}{|l|}{ Living alone } \\
\hline Yes & $n=3$ \\
\hline No & $n=6$ \\
\hline \multicolumn{2}{|c|}{ Personal care attendant } \\
\hline Yes & $n=4$ \\
\hline No & $n=5$ \\
\hline \multicolumn{2}{|l|}{ Employed } \\
\hline Yes & $n=1$ \\
\hline No & $n=8$ \\
\hline
\end{tabular}

percentages were computed for each item on the patient involvement questionnaires. The researchers then explored the within- and betweensubject group responses using all of the compiled quantitative data. Importantly, when analyzing the third aim of this study, patient-reported scores were reversed as if their survey items were also written in a negative manner. Thus, all strongly agree responses were considered to be reported as strongly disagree. The same strategy was used for reported scores of agree and disagree. This was done to allow for a more clear comparison between each group.

Qualitative remarks given by either group were transcribed verbatim to provide additional data for review. One research student, who did not participate in the interview process, reviewed the transcript of all qualitative responses given by each participant. Patient and physical therapist remarks were analyzed for commonalities, and emerging themes were developed when apparent. Qualitative remarks and subsequent emerging themes were used to help support the ratings given by each participant and to provide potential insight into the variability among Likert scores in each group.

\section{Ethics}

The study was conducted with the approval of the institutional review board of Columbia University.

\section{RESULTS}

In total, data from 30 physical therapists and 9 patients with $\mathrm{SCl}$ were included. An overview of the characteristics of the study participants is presented in Tables 2 and 3.

The first aim of this study, to describe the physical therapist's perceived involvement of their patients, revealed that the majority of physical therapists believe that they adequately involve their patients in rehabilitation. Ninety to $100 \%$ of physical therapists responded either 'Strongly Disagree' or 'Disagree' on all survey
Table 3. Physical therapist characteristics

$\begin{array}{ll}\begin{array}{l}\text { Gender } \\ \text { Male }\end{array} & n=4 \\ \text { Female } & n=26 \\ \text { Age (years) } & \\ 20-39 & n=27 \\ 40-59 & n=3 \\ & \\ \text { Years of practice } & \\ \quad<1 & n=3 \\ 1-5 & n=9 \\ 5.5-10 & n=7 \\ >10 & n=11 \\ & \\ \text { Rehabilitation setting } & \\ \text { Inpatient } & n=16 \\ \text { Outpatient } & n=12 \\ \text { Mixed } & n=2 \\ \text { Duration working with SCl population } & \\ <1 & n=7 \\ 1-10 & n=14 \\ >10 & n=9 \\ \text { Percent of SCl patients on current case load } & \\ <25 \% & n=14 \\ 25-75 \% & n=8 \\ >75 \% & n=8\end{array}$

items. However, survey items regarding gender-specific needs (item 11), community reintegration (item 9) and involvement of family/friends (item 6) yielded the lowest ratings (Figure 1).

Qualitative responses in regards to gender-specific needs were variable; however, some physical therapists felt that they lacked the appropriate knowledge or level of comfort to address these concerns. One physical therapist stated, 'It is easier for me to relate to the female than the male but I try to. There may be things we won't know or they won't ask.' Another PT reported, 'Back when I used to practice, this topic was never discussed. When I started receiving calls from my female patients asking questions about this, I knew it was time to change the program.' Many physical therapists also reported that they attempt to answer patients' concerns regarding gender issues; however, many felt the need to refer their patients or recommend they speak with other individuals with $\mathrm{SCl}$ for advice. One PT said, 'I do the best I can, then refer them to appropriate disciplines or mentor for more details.' Another physical therapist gave examples of what was discussed with patients regarding gender-specific needs. For female patients, these issues often were in regard to childbirth, whereas with male patients, return to sport and sexual issues were discussed more often.

A few physical therapists gave qualitative remarks in regards to restrictions in community reintegration. In general, physical therapists believe that they do the best they can to prepare their patients for a return to their community; however, they are limited by insurance regulations and a relatively short length of stay. One physical therapist stated, 'It can take two years to adjust to the injury, there are time constraints, insurance companies cut off.' Multiple comments were given in regards to issues with time constraints of their facilities. For example, another physical therapist stated, 'The only issue with strongly disagree is length of stay, we cannot keep them as long as we would like.'

Physical therapists also gave supporting evidence in regards to their ratings on involvement of patients' families and friends. In general, most physical therapists encouraged patients' families and friends to be involved in their rehabilitation. One physical therapist said, 'I do as much family and caregiver training as 
11. I don't address my patient's gender specific needs.

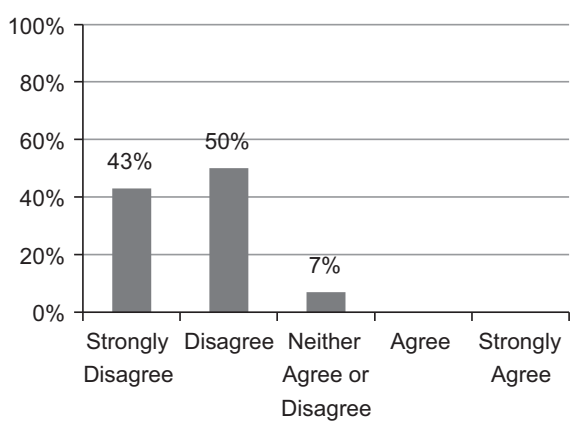

9. I don't feel that I adequately prepare my patients for functioning in the community after discharge.

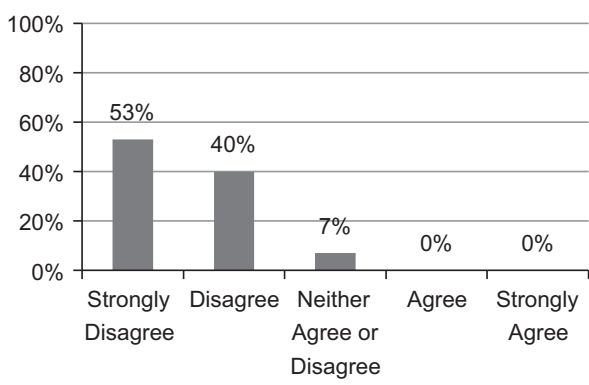

6. I don't involve the patient's

family/friends in their PT therapy.

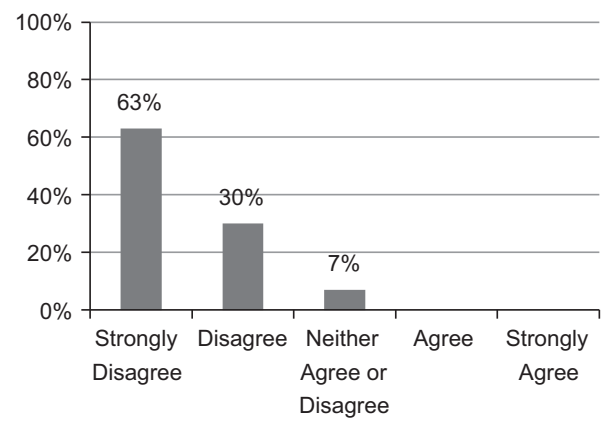

Figure 1. Lowest scoring responses to physical therapist survey items 11, 9 and 6 expressed as percentages.

6. My friends/family were involved in my therapy.

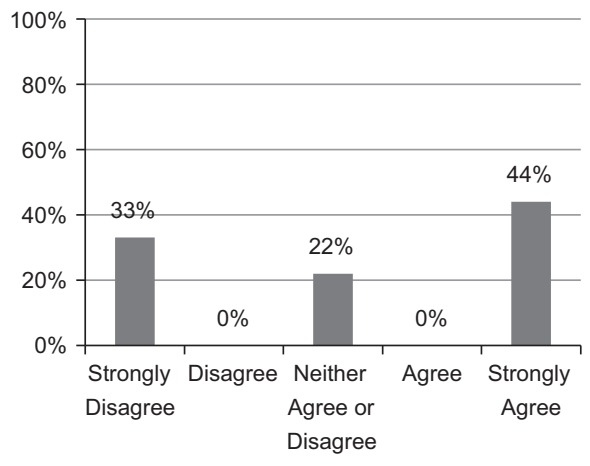

3. My personal goals for rehabilitation were taken into account for planning of treatment.

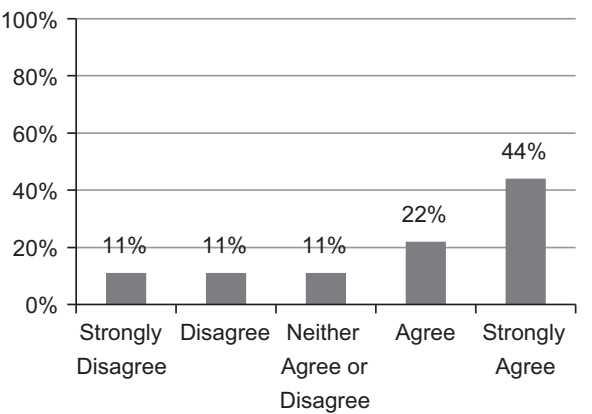

11. I felt as though my gender specific needs were addressed by my physical therapist

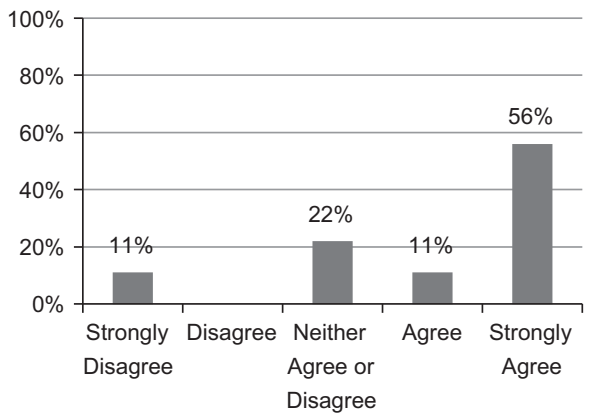

Figure 2. Lowest scoring responses to the patient survey items 6,3 and 11 expressed as percentages. 
Survey Item 3

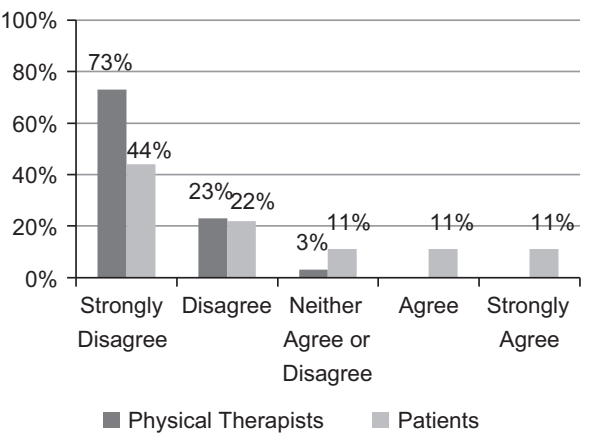

Survey Item 6

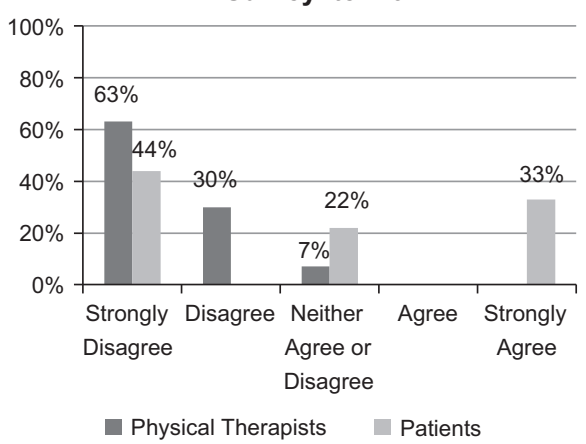

Figure 3. Largest discrepancies between PT and patient survey responses; items 3 and 6 were presented as percentages. The Likert scale for patient-reported scores was reversed to allow a more clear comparison with physical therapists' scores.

possible, and give them easy tasks to do. We encourage them to go to classes too.' However, many PTs noted that social support is often variable. One PT reported, 'Sometimes they don't want family involved or sometimes they are not available.'

The second aim, to describe the perceived involvement from the perspective of the patient, revealed that the majority of patients did feel included in their rehabilitation. Overall, the range of patient responses of either 'Strongly Agree' or 'Agree' on all survey items was $44-100 \%$. The patients' lowest reported ratings were obtained on survey items regarding involvement of family/ friends (item 6), personalized goals (item 3) and gender-specific needs (item 11; Figure 2).

In general, patients in this study were far less likely to give qualitative responses in addition to each survey item they ranked. However, in regards to gender-specific issues, two patients gave examples to support their Likert ratings. Both patients believed that their specific gender needs were not facilitated by their physical therapist. One patient stated, 'We never talked about anything related to sex, and I wouldn't expect it from the PT.' Another patient said, 'My PT was a woman and things like sex were never discussed. I watched an outdated and unrealistic video about this. I found these things out from talking to other $\mathrm{SCl}$ patients. I felt this holds patients back a little bit after injury since we're never educated and we have to wait to learn this information on our own.' No comments were given in support of ratings for survey item 3 , in regards to establishing personalized goals or item 6, involvement of friends/family.

The third aim of this study, to compare how PTs and patients perceive involvement, revealed that physical therapists and patients were in agreement over the patients' involvement in rehabilitation. Physical therapists rated perceived involvement consistently higher on all items when compared with the patients' responses. Attending to the patients' gender-specific needs and involvement of family/friends yielded two of the three lowest scoring items in either group. Survey items in regards to personalized patient goals (item 3) and involvement of friends/ family (item 6) yielded the largest inconsistencies between physical therapist and patient-reported scores (Figure 3).

No comments were given by the patients to explain the discrepancies between groups and their rankings reported on survey items 3 and 6 . However, physical therapists reported that patients' social support is often unavailable and thus would not be included in their patients' rehabilitation. In regards to personalized goals, many physical therapists felt strongly that they incorporated patient goals in their rehabilitation; however, patients often set goals that are unrealistic. One PT said, 'Coach them to keep their goals realistic. This is our first question. If it is someone interested in walking and it is unrealistic we get redirected but will work in why as PT progresses.'

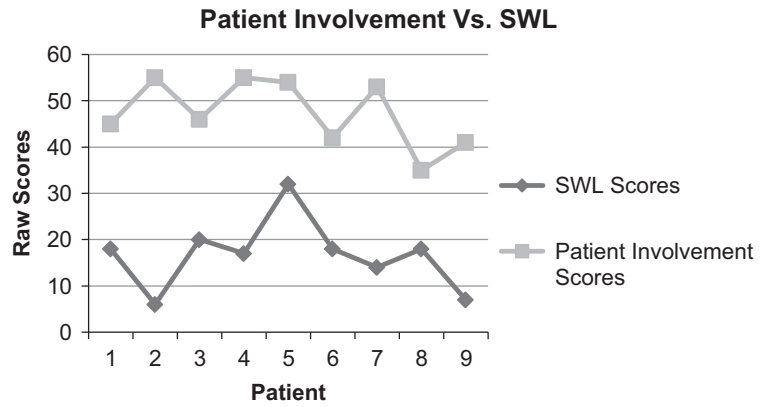

Figure 4. Total raw scores for the patient involvement questionnaire and SWL for all study participants.

The final objective of this study was to compare patients' perceived involvement in rehabilitation with SWL scores. Comparing these responses, a high score on patient involvement did not necessarily yield a high score on SWL (Figure 4). In fact, the scores were quite variable. However, it was observed that the youngest and oldest participants, patient 2 and 9, reported the lowest SWL scores, respectively (Figure 4).

\section{DISCUSSION}

Our results with a small sample of only 30 PTs felt that they involve their patients in rehabilitation and 9 patients also responded overall that therapists involved them in the rehabilitation process. This sample of physical therapists and patients were in agreement with each other that the patient is involved and participating in PT; however, PTs consistently scored higher than the patients on most survey items. The therapists offered more qualitative statements than the patients therefore designing of a future survey for validation may want to be negatively worded for both groups. The patient involvement scores and SWLS scores were so variable from this small sample that further research is recommended with a larger sample size to examine whether patient involvement in PT rehabilitation has an impact on SWL.

Items 11 and 6 were two of the lowest scoring items in both groups. Item 6 related to family and friends involvement in rehabilitation. PTs did comment that they do make an effort to involve family; however, the availability of family members and the variability of how involved families are during rehabilitation appear to be quite individualized. Patients did not offer any comments related to this item. Previous research has indicated that patient preferences for family involvement and the extent of the involvement may vary. ${ }^{3}$ Item 11 was in regards to genderspecific needs. A few PTs expressed that they lacked the appropriate knowledge or level of comfort to address these concerns. Other physical therapists commented that they do the 
best they can to address gender-related issues; however, they often referred to other disciplines or patient mentors when their services alone were inadequate. Two patients expressed that their specific gender needs were not facilitated by their physical therapist.

Future research appears to be needed to explore the role of physical therapists as part of the rehabilitation team in addressing sexuality and gender-specific needs in $\mathrm{SCl}$. In a recent study by Sale et al. ${ }^{14}$ only $31 \%$ from a sample of 403 individuals with SCl were satisfied with their sexual life. Incorporating a satisfying sexual life has been identified as a new issue to include in current rehabilitation programs; ${ }^{14}$ however, the roles of the rehabilitation team may differ depending on geographic region and culture. It appears from our small sample both PTs and patients vary in their perception of what gender-specific needs should be included as they relate to the PT's role. The wording of this survey item may not be clear to many of the responders and would need further clarification in future versions of the survey.

The last two lowest scoring items were community integration as rated by the physical therapist and personalized goals as rated by the patients. Although $93 \%$ of the PTs felt they prepared patients for community integration, $7 \%$ were neutral. Qualitative comments were helpful in clarifying these responses related to short length of stay for inpatient rehabilitation. The length of stay for inpatient rehabilitation in the United States has declined and is limited to an average of 14-37 days for a diagnoses of paraplegia or tetraplegia, respectively, ${ }^{15}$ many individuals may therefore receive more community preparation after discharge on the outpatient basis. Interestingly, 20\% of the PTs commented that they felt restricted by limited time but overall felt they did prepare their patients for community level participation. Future research comparing inpatient versus outpatient involvement in therapy may offer more clarification regarding transition to the community.

The survey question that yielded the largest discrepancy in Likert ratings between groups was item 3 in regards to personalized goals. Only $66 \%$ of the patients agreed or strongly agreed as compared with $93 \%$ of the therapists that felt they included personalized goals in their program planning. Because none of the subjects offered qualitative comments regarding this survey item, we cannot identify what factors contributed to the lower ratings. There are a few considerations to explore, as this is an area that can heavily impact the rehabilitation experience for an individual with $\mathrm{SCl}$. The ability to participate in the practice of activity limitations and participation restrictions during rehabilitation could have a role in patient involvement. One participant was unable to practice activity related skills secondary to bilateral upper extremity fractures, thus his response reflected in his low rating of this item. The inability to partake in functional training may impact both personal goals and community preparation. Eight PTs commented that the patients' goals might be unrealistic; for example, returning to walking too early. This common comment provides only one explanation. Previous work by Lindberg ${ }^{3}$ demonstrated that newly injured individuals might rely more on the staff for their planning, and their participation increased as their health status improved. This may only partially explain our study findings. Therefore, future qualitative and quantitative research is needed to identify variables impacting the inclusion of patients' goals during the rehabilitation process.

Our survey instrument is only a preliminary glance to explore this topic and has not been validated a requirement for future studies. Our sample was a small sample of convenience with geographical limitations, thus our preliminary descriptive results would require a larger sample from a broader region. Patients were less likely to include comments and examples as compared with the PT that may be due to the positive wording of their questionnaire, whereas the PT's questions were negatively worded, perhaps evoking a comment. Consideration of the wording of the survey requires further investigation.

In conclusion, our results indicate that physical therapists and individuals with $\mathrm{SCl}$ are in agreement regarding involvement in PT rehabilitation on many of the survey items. Therapists' tended to rank the survey items higher. Personalized goals had the largest discrepancy between groups indicating a need for further research. In addition, both the patients and PTs noted variability regarding involvement of family and friends in the rehabilitation process. The item, gender-specific needs, was also scored low by both groups, suggesting the need for further research clarification on the therapist role in this area.

\section{ACKNOWLEDGEMENTS}

We thank all of the physical therapists and individuals with a spinal cord injury who volunteered to participate in this study.

\section{COMPETING INTERESTS}

The authors declare no conflict of interest.

\section{REFERENCES}

1 Sisto S, Druin E, Sliwinski MM. Spinal Cord Injuries: Management and Rehabilitation. Elsevier Mosby: St Louis, MO, USA, 2008.

2 Sand A, Karlberg I, Kreuter M. Spinal cord injured persons' conceptions of hospital care, rehabilitation, and a new life situation. Scand J Occup Ther 2006; 13 183-192.

3 Lindberg J, Krueter M, Taft C, Person L-O. Patient participation in care and rehabilitation from the perspective of patients with spinal cord injury. Spinal Cord 2013; 51: 834-837.

4 Papadimitriou C. 'It was hard but you did it': the co-production of 'work' in a clinical setting among spinal cord injured adults and their physical therapists. Disabil Rehabil 2008; 30: 365-374.

5 Tooth LR, Ottenbacher KJ, Smith PM, Illig SB, Tinn RT, Granger CV. Satisfaction with medical rehabilitation after spinal cord injury. Spine 2004; 29: 211-219.

6 Ripat JD, Woodgate RL. Self-perceived participation among adults with spinal cord injury: a grounded theory study. Spinal Cord 2012; 50: 908-914.

7 Pellatt G. Patient-professional partnership in spinal cord injury rehabilitation. Brit J Nurs 2004; 13: 948-953.

8 Garrino L, Curto N, Decorte R, Felisi N, Matta E, Gregorino S et al. Towards personalized care for persons with spinal cord injury: a study on patient's perceptions. J Spinal Cord Med 2011; 34: 67-75.

9 Carpenter C, Forwell SJ, Jongbloed LE, Backman CL. Community participation after spinal cord injury. Arch Phys Med Rehabil 2007; 88: 427-433.

10 Hammell KW. Experience of rehabilitation following spinal cord injury: a meta-synthesis of qualitative findings. Spinal Cord 2007; 45: 260-274.

11 Diener E, Emmons RA, Larsen RJ, Griffin S. The satisfaction with life scale. J Pers Assess 1985; 49: 71-75.

12 Pavot W, Diener E, Randall Colvin C, Sandvik E. Further validation of the satisfaction with life scale: evidence for the cross method convergence of well-being measures. J Pers Assess 1991; 57: 149-161.

13 Post M, VanLeeuwen C, Van Koppenhagan C, de Groot S. Validity of the life satisfaction questions, the life satisfaction questionnaire, and the satisfaction with life scale in persons with spinal cord injury. Arch Phys Med Rehabil 2012; 93: 1832-1837

14 Sale P, Mazzarella F, Pagliacci M, Agosti M, Felzani G, Franceschini M. Predictors of changes in sentimental and sexual life after traumatic spinal cord injury. Arch Phys Med Rehabil 2012; 93: 1944-1949.

15 National Spinal Cord Injury Statistical Center. Annual Statistical Report for the Spinal Cord Injury Model Systems- Complete Public Version. University of Alabama at Birmingham: Birmingham, AL, USA, 2013. 